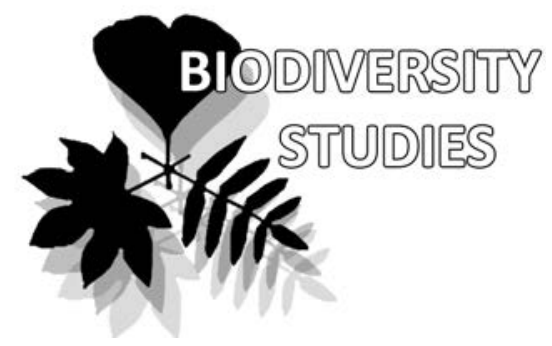

\title{
Phytoplankton in the Coastal Waters of Russky Island, Peter the Great Bay, Sea of Japan
}

Olga G. Shevchenko ${ }^{1,2 *}$, Anna A. Ponomareva ${ }^{1}$, Maria A. Shulgina ${ }^{1}$ \& Tatiana Yu. Orlova ${ }^{1}$

\author{
Olga G. Shevchenko $1,2 *$ \\ e-mail: 713553@mail.ru \\ Anna A. Ponomareva \\ e-mail: anna_andreevna7@mail.ru \\ Maria A. Shulgina ${ }^{1}$ \\ e-mail: annekee@mail.ru \\ Tatiana Yu. Orlova ${ }^{1}$ \\ e-mail: torlova06@mail.ru
}

${ }^{1}$ National Scientific Center of Marine Biology FEB RAS, Vladivostok, Russia

${ }^{2}$ Far Eastern State Technical Fisheries University, Vladivostok, Russia

\section{* corresponding author}

Manuscript received: 28.06 .2018

Review completed: 15.03.2019

Accepted for publication: 18.03.2019

Published online: 19.03.2019

\begin{abstract}
A B S T R A C T
The article presents an annotated list of microalgal species in the coastal waters off Russky Island (Sea of Japan) based on original and literature data. A total of 254 taxa of microalgae from ten classes are identified. Descriptions and photographic illustrations are provided for the diatom species of the genus Skeletonema and prymnesiophyta Pseudohaptolina sorokinii, which are rare in the seas of Russia. Information on 20 species of potentially toxic microalgae observed in the study area is also provided.
\end{abstract}

K e y w o r d s : marine, phytoplankton, flora, ecology, Russky Island, Sea of Japan

\section{P E 3 Ю M E}

Шевченко О.Г., Пономарева А.А., Шульгина М.А., Орлова Т.Ю. Фитопланктон прибрежных воА острова Русский, залив Петра Великого, Японское море. В работе преАстав ен аннотированный список микровоАорослей прибрежных вод острова Русский (Японское море), составленный на основе оригинальных сведений и данных митературы. Обнаружено 254 таксона микроводорослей, относящихся 10 классам. Приведены описания и даны фототаблицы редких Аля морей России виАов диатомовых рода Skeletonema и примнезиофитовой водоросли Pseudohaptolina sorokinii. Включены сведения о 20 видах потенциально токсичных микроводорослей. Аанная работа содержит сведения о составе фитопланктона исследованной акватории до начала ее активной эксплуатации.

КАючевые слова: морской фитопланктон, флора, экология, остров Русский, Японское море
Russky Island is located in Peter the Great Bay of the Sea of Japan, near the southern tip of the Muravyov-Amursky Peninsula. The island is washed by the waters of Amur Bay in the west and Ussuri Bay (both are smaller subordinate bays in Peter the Great Bay) in the east and in the south. The bays are connected by the Eastern Bosphorus Strait bordering Russky Island in the north. Amur Bay is one of the most studied areas of the northwestern Sea of Japan. More than 30 papers dealing with the research of phytoplankton from Amur Bay have been published since the beginning of the last century. The results of an almost hundred-yearlong study of microalgal flora in this bay are summarized by Orlova et al. (2009). The phytoplankton of Ussuri Bay is significantly less studied; there are only two publications providing data on investigation of microalgae from this bay (Selina 1988, Begun 2004).

Species composition and abundance of phytoplankton are widely used for the assessments of the human impact on water areas and may serve as ecosystem indicators due to the ability of microalgae to promptly respond to changes in the aquatic environment (Cloern \& Jassby 2010). The upcoming necessity to evaluate the anthropogenic pressures on the coastal waters off Russky Island makes inventorying the flora of this water area timely and relevant.
The purpose of our study was to summarize the data on the long-term research of phytoplankton from the coastal waters of Russky Island, as well as to compile a floral list with quantitative characteristics of each taxon for different seasons.

\section{MATERIAL AND METHODS \\ Environmental conditions of the study area}

The climatic conditions of the northwestern part of Russky Island differ from those in its southeastern part facing the open sea. During the summer monsoon period the southeastern part of the island is often exposed to fogs and colder than the northwest part. Most precipitation falls in summer. The mean air temperature ranges from $0^{\circ} \mathrm{C}$ to $-12^{\circ} \mathrm{C}$ in winter and from $14^{\circ} \mathrm{C}$ to $21^{\circ} \mathrm{C}$ in summer. During winter, the temperature of the coastal waters off the island falls down to $-1.9^{\circ} \mathrm{C}$; the water reaches its highest temperature, up to $25^{\circ} \mathrm{C}$, in August. Freeze-up usually begins in mid December; the coastal strip of the sea off Russky Island is covered with ice up to $1 \mathrm{~m}$ and more thick until the middle of March.

\section{Data sampling and analysis}

Phytoplankton was sampled in the coastal waters of Ussuri Bay and Peter the Great Bay around Russky Island 
(Fig. 1, Table 1). In 2007 and 2008, sampling was conducted with the research vessel Larga; in 2012-2015, sampling was carried out by the research team of the Primorsky Aquarium, Branch of the National Scientific Center of Marine Biology, Far Eastern Branch of the Russian Academy of Sciences (NSCMB FEB RAS), at the monitoring stations. In winter, phytoplankton was sampled through a hole drilled in the sea ice. Samples were taken with a 5-liter Niskin bottle from the surface horizon. One liter of the sample was fixed with Utermöhl's solution and concentrated by sedimentation (Utermöhl 1958, Sukhanova 1983). The material was examined in a Nageotte counting chamber with a volume of $0.05 \mathrm{~mL}$. A total of 497 phytoplankton samples were studied.
Microalgae were identified under a light microscope Olympus BX 41 (LM). The fine structure of valves was examined with a transmission electron microscope JEM100 JEOL S (TEM) and a scanning electron microscope Carl Zeiss Leo 430 (SEM). Material for TEM was prepared according to the standard procedure (Hasle \& Fryxell 1970, Shevchenko \& Ponomareva 2015). Algae were considered to be blooming at concentrations exceeding $10^{6}$ cells $/ \mathrm{L}$ (Colijn 1992).

In this article we use the taxonomic classification proposed by Guiry \& Guiry (2012). Species within the classes are alphabetically ordered (Table 2 ). The synonymy given here reflects all nomenclatural changes made since 2008.

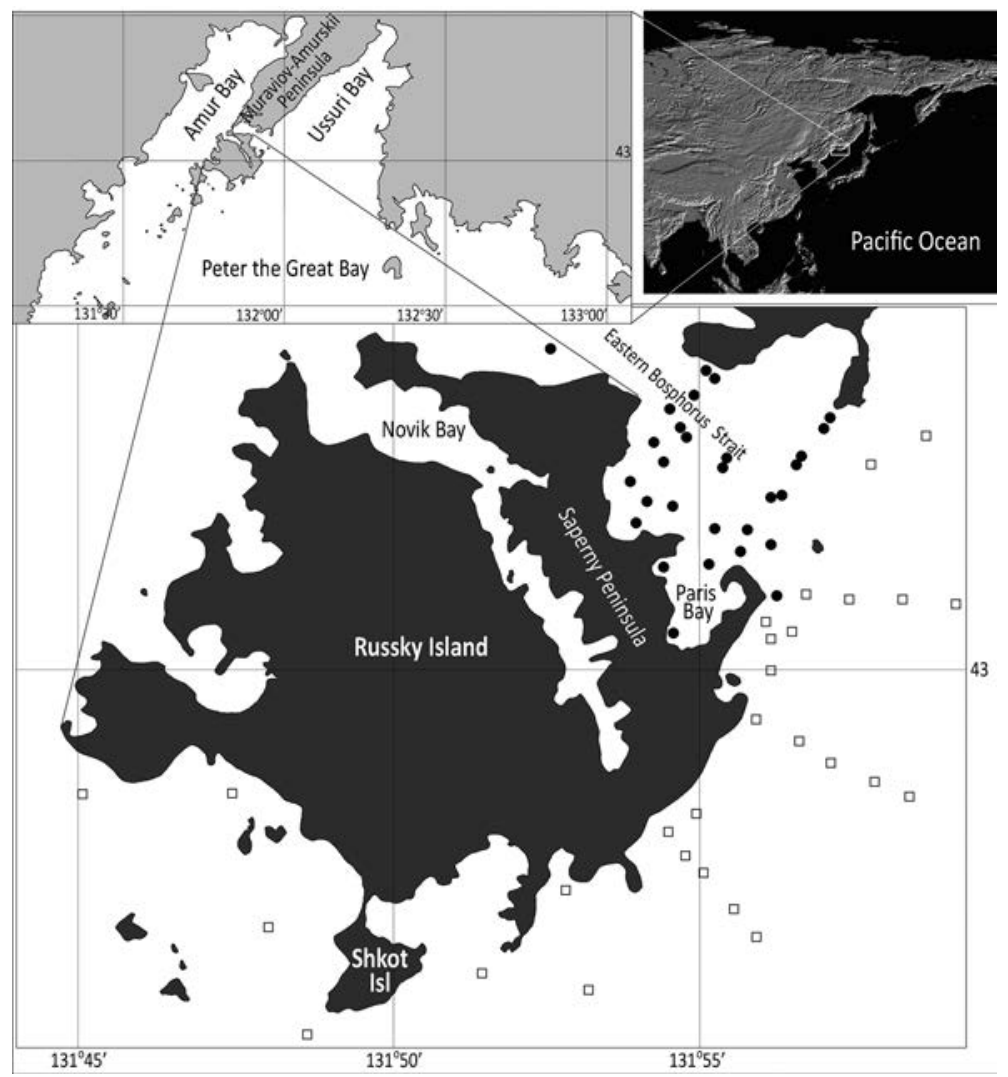

Figure 1 Map of phytoplankton sampling stations off Russky Island. Stations in Eastern Bosphorus Strait are indicated by circles; in Ussuri Bay, by squares

\section{RESULTS}

The original studies resulted in an annotated list of phytoplankton from the coastal waters of Russky Island. The list provides information on 254 species and intraspecific taxa of microalgae from ten classes (Table 2). The highest species diversity was recorded for Bacillariophyceae (133 species and 5 intraspecific taxa) and Dinophyceae (109). Other classes were represented by smaller numbers of species: Euglenoidea, 4; Dictyochophyceae, 4; Chlorophyceae, 3; Cryptophyceae, 2; Cyanophyceae, 2; Chrysophyceae, 1; Ebriophyceae, 1; and Prymnesiophyceae, 1 species. Among diatoms, the genus Chaetoceros was the richest in species (39 species and intraspecific taxa); among dinoflagellates, the genus Protoperidinium had the greatest variety of species (32 species).

During the study period, such species of planktonic microalgae as Pseudohaptolina sorokinii of the Prymnesiophycea and diatoms of the genus Skeletonema, which are rare in the seas of Russia, were recorded. When examining colonies of Skeletonema with electron microscopy, we identified S. costatum, S. dobrnii, S. grethae, $S$. japonicum and $S$. marinoi (Figs 2, 3). The article provides descriptions of the species of the genus Skeletonema and Pseudohaptolina sorokinii from the study area.

Table 1. Characteristics of the material collected.

\begin{tabular}{|c|c|c|c|c|c|}
\hline \multirow{2}{*}{ Area } & \multirow{2}{*}{ Date of sampling } & \multicolumn{2}{|c|}{ Quantity } & \multirow{2}{*}{ Longitude, E } & \multirow{2}{*}{ Latitude, $\mathbf{N}$} \\
\hline & & stations & samples & & \\
\hline & $08.02 .2007-28.02 .2007$ & 12 & 16 & $131^{\circ} 5355^{\prime \prime}-131^{\circ} 5603^{\prime \prime}$ & $43^{\circ} 0140^{\prime \prime}-43^{\circ} 0325^{\prime \prime}$ \\
\hline Eastern & 13.04 .2007 & 2 & 2 & $131^{\circ} 52^{\prime} 34^{\prime \prime}-131^{\circ} 55^{\prime} 36^{\prime \prime}$ & $43^{\circ} 02^{\prime} 38^{\prime \prime}-43^{\circ} 04^{\prime} 08^{\prime \prime}$ \\
\hline Bosphorus & 03.05 .2007 & 6 & 8 & $131^{\circ} 5425^{\prime \prime}-131^{\circ} 57^{\prime} 22^{\prime \prime}$ & $43^{\circ} 01^{\prime} 36^{\prime \prime}-43^{\circ} 03^{\prime} 53^{\prime \prime}$ \\
\hline \multirow{2}{*}{ Strait } & 02.09.2008; 04.09.2008 & 9 & 21 & $131^{\circ} 51^{\prime} 13^{\prime \prime}-131^{\circ} 5638^{\prime \prime}$ & $43^{\circ} 01^{\prime} 57^{\prime \prime}-43^{\circ} 03^{\prime} 39^{\prime \prime}$ \\
\hline & $14.12 .2012-17.11 .2015$ & 2 & 335 & $131^{\circ} 5420^{\prime \prime}-131^{\circ} 55^{\prime} 51^{\prime \prime}$ & $43^{\circ} 00^{\prime} 27^{\prime \prime}-43^{\circ} 01^{\prime} 50^{\prime \prime}$ \\
\hline \multirow{5}{*}{ Ussuri Bay } & 20.02 .2007 & 3 & 3 & $131^{\circ} 56^{\prime} 15^{\prime \prime}-131^{\circ} 5628^{\prime \prime}$ & $43^{\circ} 00^{\prime} 17^{\prime \prime}-43^{\circ} 01^{\prime} 10^{\prime \prime}$ \\
\hline & 13.04 .2007 & 8 & 8 & $131^{\circ} 45^{\prime} 17^{\prime \prime}-131^{\circ} 56^{\prime} 14^{\prime \prime}$ & $42^{\circ} 55^{\prime} 46^{\prime \prime}-43^{\circ} 00^{\prime} 55^{\prime \prime}$ \\
\hline & 03.05 .2007 & 12 & 16 & $131^{\circ} 53^{\prime} 07^{\prime \prime}-131^{\circ} 59^{\prime} 15^{\prime \prime}$ & $42^{\circ} 55^{\prime} 42^{\prime \prime}-43^{\circ} 01^{\prime} 10^{\prime \prime}$ \\
\hline & $03.09 .2008-04.09 .2008$ & 17 & 39 & $131^{\circ} 5453^{\prime \prime}-131^{\circ} 59^{\prime} 03^{\prime \prime}$ & $42^{\circ} 55^{\prime} 42^{\prime \prime}-43^{\circ} 01^{\prime} 10^{\prime \prime}$ \\
\hline & 26.03.2013-20.10.2015 & 1 & 49 & $131^{\circ} 56^{\prime} 12^{\prime \prime}-131^{\circ} 56^{\prime} 14^{\prime \prime}$ & $44^{\circ} 00^{\prime} 54^{\prime \prime}-44^{\circ} 00^{\prime} 55^{\prime \prime}$ \\
\hline
\end{tabular}


Skeletonema costatum (Greville) Cleve, 1873 (Fig. 2: A, B)

Description. Cells cylindrical, 9-12 $\mu \mathrm{m}$ in diameter, joined into colonies by long straight fultoportula processes. Valves circular, slightly convex in the center, strongly silicified. Each fultoportula process with a large pore at its base. The intercalary fultoportula processes differ in shape from the terminal ones. The rimoportula is located inside the ring of the fultoportula processes in intercalary and terminal valves.

Distribution. Its distribution in the World Ocean needs to be clarified. The species is reliably reported from along the coast of Hong Kong Island (Greville 1866), Northern Queensland (Australia); in the Atlantic Ocean it occurs in the coastal waters of the USA, Uruguay, Brazil (Sarno et al.
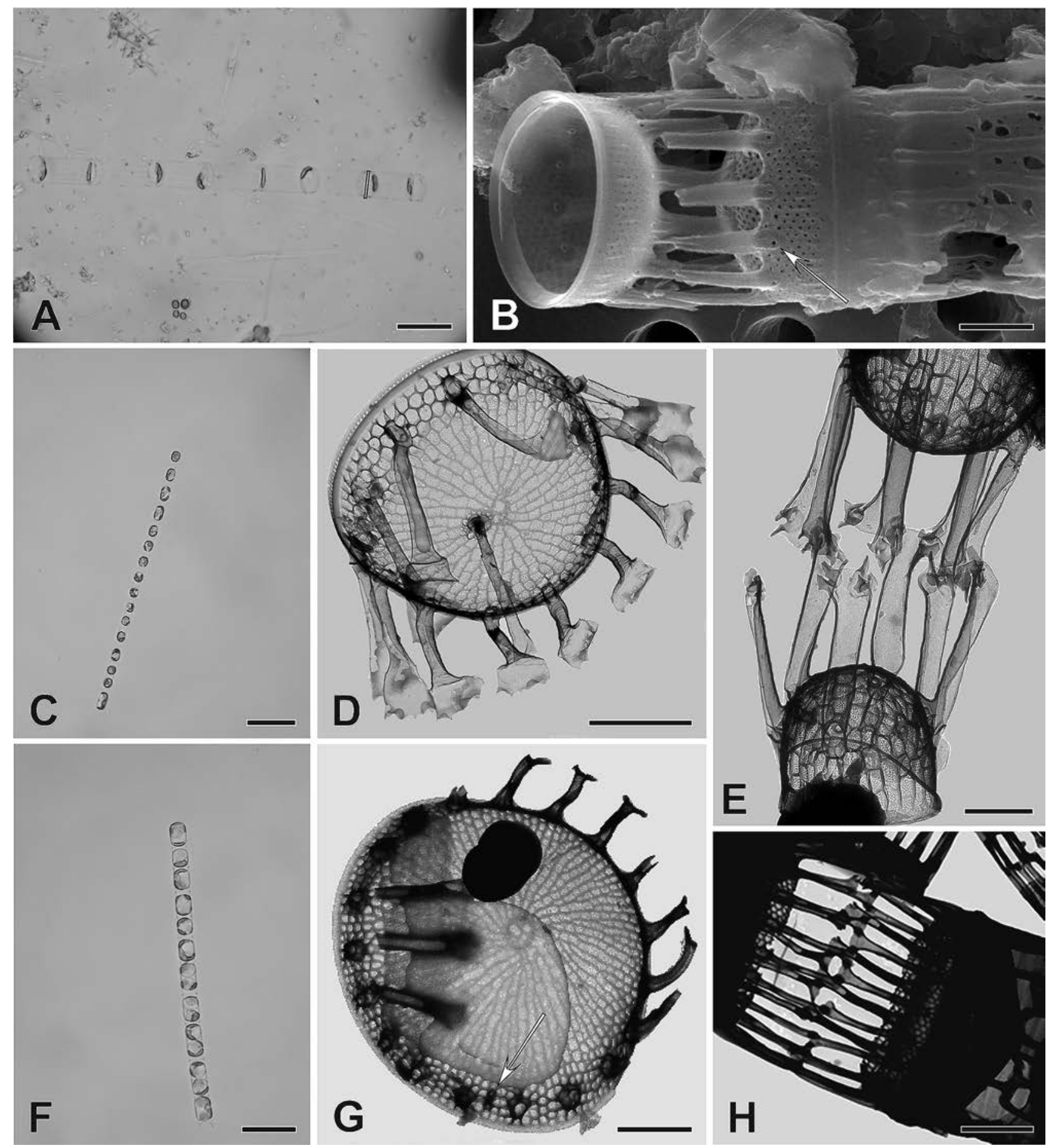

Figure 2 Skeletonema costatum (Greville) Cleve, 1873: A - fragment of colony, B - intercalary cells, large pore at the base of fultoportula process (arrowhead); Skeletonema dohrnii Sarno et Kooistra 2005: C - general appearance of colony, D - terminal valve, rimoportula process located close to valve center, E - two intercalary valves, shape of fultoportula processes; Skeletonema grethae Zingone et Sarno 2005: F colony of cells, $\mathrm{G}$ - intercalary valve, rimoportula process (arrowhead), $\mathrm{H}$-adjacent valves, linkage of fultoportula processes. A, C, F - LM, B - SEM, D, E, G, H - TEM. Scale: E $=1 \mu \mathrm{m}, \mathrm{B}, \mathrm{D}, \mathrm{G}, \mathrm{H}=2 \mu \mathrm{m}, \mathrm{A}, \mathrm{C}=10 \mu \mathrm{m}, \mathrm{F}=20 \mu \mathrm{m}$ 
Table 2. List of planktonic microalgae in the coastal waters of Russky Island, Peter the Great Bay, Sea of Japan.

\begin{tabular}{|c|c|}
\hline Species & $\begin{array}{c}\text { Month } \\
123456789101112\end{array}$ \\
\hline DICTYOCHOPHYCEAE & \\
\hline Dictyocha fibula Ehrenberg & $\begin{array}{llllllllllll}1 & 1 & 2 & 1 & 0 & 0 & 1 & 2 & 2 & 3 & 3 & 1\end{array}$ \\
\hline $\begin{array}{l}\text { Octactis speculum (Ehrenberg) Chang, } \\
\text { Grieve et Sutherland }\end{array}$ & $\begin{array}{llllllll}0 & 1 & 1 & 2 & 1 & 1 & 1 & 2\end{array}$ \\
\hline $\begin{array}{l}\text { Octactis octonaria (Ehrenberg) Hovasse } \\
\text { Vicicitus globosus (Hara et Chihara) } \\
\text { Chang = Chattonella globosa Hara et }\end{array}$ & 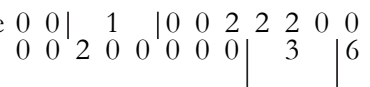 \\
\hline
\end{tabular}

Chang = Chattonella globosa Hara et

\section{CHRYSOPHYCEAE}

Dinobryon balticum (Schütt)

Lemmermann

Ebria tripartita (Schütt) Lemmermann $\begin{array}{llllllllllllll}0 & 0 & 1 & 1 & 1 & 0 & 2 & 2 & 2 & 2 & 1 & 0\end{array}$ Ebria tripartita (Schutt) Lemm

Achnanthes longipes Agardh

Actinoptychus senarius (Ehrenberg)

Ehrenberg

Amphora sp.

Asterionella formosa Hassal

Asterionellopsis glacialis (Castracane)

Round

Asteromphalus flabellatus (Brébisson)

Greville

Asteromphalus heptactis (Brébisson)

Ralfs

Attheya longicornis Crawford et

Gardner

Bacteriastrum furcatum Schadbolt

Bacteriastrum byalinum Lauder

Bellerochea malleus (Brightwell) Van

Heurck

Brockmanniella brockemannii (Husted) Hasle

Cerataulina dentata Hasle

Cerataulina pelagica (Cleve) Hendey

Chaetoceros affinis Lauder

Chaetoceros anastomosans Grunow

Chaetoceros atlanticus Cleve

Chaetoceros borealis Bailey

Chaetoceros concavicornis Mangin

Chaetoceros constrictus Gran

Chaetoceros contortus Schütt

Chaetoceros convolutus Castracane

Chaetoceros costatus Pavillard

Chaetoceros curvisetus Cleve

Chaetoceros danicus Cleve

Chaetoceros debilis Cleve

Chaetoceros decipiens Cleve

Chaetoceros diadema (Ehrenberg) Gran

Chaetoceros didymus Ehrenberg

Chaetoceros furcillatus Bailey

Chaetoceros ingolfianus Ostenfeld

Chaetoceros laciniosus F. Schütt

Chaetoceros lauderi Ralfs

Chaetoceros lorenzianus Grunow

Chaetoceros mitra (Bailey) Cleve

Chaetoceros paradoxus Cleve

Chaetoceros pendulus Karsten

Chaetoceros peruvianus Brightwell

Chaetoceros protuberans Lauder =

Chaetoceros didymus var. protuberan

Lauder) Gran et Yendo

Chaetoceros psendobrevis Pavillard

Chaetoceros pseudocrinitus Ostenfeld

Chaetoceros pseudocurvisetus Mangin

Chaetoceros radicans $\mathrm{F}$. Schütt

Chaetoceros salsugineus Takano

Chaetoceros seiracanthus Gran

Chaetoceros similis Cleve

Chaetoceros simplex Ostenfeld

Chaetoceros socialis f. socialis Lauder

Chaetoceros socialis $\mathrm{f}$. radians (F. Schütt)

Proschkina-Lavrenko

Chaetoceros teres Cleve

Chaetoceros tortissimus Gran

Cocconeis distans Gregory

Cocconeis scutellum Ehrenberg

Corethron bystrix Hensen

Coscinodiscus granii Gough

Coscinodiscus oculus iridis Ehrenberg

Coscinodiscus perforatus Ehrenberg

Cyclotella sp.

Cylindrotheca closterium (Ehrenberg) Reimann et Lewin

Dactyliosolen fragilissimus (Bergon)

Hasle $=$ Rhizosolenia fragilissima

Bergon $\begin{array}{llllllllllll}1 & 0 & 1 & 2 & 6 & 0 & 0 & 0 & 0 & 0 & 0 & 1\end{array}$

$\begin{array}{lllllllllllll}0 & 0 & 0 & 0 & 0 & 0 & 0 & 1 & 0 & 0 & 1 & 0\end{array}$ $\begin{array}{lllllllllllll}0 & 0 & 0 & 0 & 0 & 0 & 0 & 0 & 0 & 2 & 0 & 0\end{array}$

$\begin{array}{lllllllllllll}0 & 0 & 0 & 1 & 0 & 1 & 1 & 1 & 1 & 1 & 0 & 0\end{array}$ $\begin{array}{lllllllllllll}0 & 2 & 0 & 1 & 1 & 0 & 0 & 0 & 0 & 2 & 0 & 0\end{array}$ $\begin{array}{llllllllllll}0 & 2 & 2 & 1 & 1 & 0 & 0 & 0 & 1 & 3 & 2\end{array}$ $\begin{array}{llllllllllll}0 & 0 & 0 & 0 & 0 & 0 & 0 & 0 & 0 & 1 & 0 & 0\end{array}$ $\begin{array}{lllllllllllll}0 & 0 & 0 & 0 & 0 & 0 & 0 & 0 & 0 & 2 & 0 & 0\end{array}$ $\begin{array}{lllllllllllll}0 & 3 & 1 & 1 & 0 & 0 & 0 & 0 & 1 & 1 & 0 & 0\end{array}$

$\begin{array}{llllllllllll}1 & 0 & 0 & 0 & 0 & 0 & 0 & 1 & 2 & 1 & 0\end{array}$ $\begin{array}{lllllllllllll}0 & 0 & 0 & 0 & 0 & 0 & 0 & 2 & 0 & 2 & 0 & 0\end{array}$

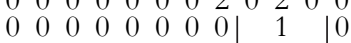
$\begin{array}{llllllllllll}0 & 0 & 0 & 0 & 0 & 2 & 2 & 2 & 0 & 0 & 1 & 0\end{array}$

\begin{tabular}{llllll|l|llll}
0 & 0 & 0 & 0 & 1 & 1 & 3 & 3 & 3 & 2 & 1
\end{tabular} $\begin{array}{llllllllllll}0 & 2 & 1 & 1 & 2 & 0 & 1 & 0 & 2 & 3 & 1 & 0\end{array}$ \begin{tabular}{ll|llllllllll} 
& 3 & 0 & 0 & 0 & 1 & 2 & 3 & 3 & 3 & 1 & 0
\end{tabular} $\begin{array}{llllllllllll}0 & 1 & 0 & 0 & 0 & 0 & 0 & 0 & 0 & 0 & 0 & 0\end{array}$ \begin{tabular}{lllllll|llll}
0 & 2 & 1 & 0 & 0 & 1 & 1 & 0 & 0 & 0 & 0
\end{tabular} $\begin{array}{llllllllllll}0 & 0 & 0 & 0 & 0 & 1 & 0 & 0 & 0 & 0 & 0 & 0\end{array}$ $\begin{array}{llllllllllll}0 & 0 & 0 & 0 & 0 & 0 & 0 & 0 & 0 & 2 & 1 & 0\end{array}$ \begin{tabular}{lllllll|llll}
$\mid$ & 1 & $\mid$ & 0 & 0 & 0 & 1 & 1 & 3 & 0 & 0
\end{tabular} $\begin{array}{llllllllllll}0 & 2 & 2 & 3 & 2 & 2 & 0 & 2 & 2 & 4 & 0 & 0\end{array}$ $\begin{array}{lllllllllllll}0 & 1 & 2 & 2 & 1 & 0 & 1 & 0 & 1 & 2 & 1 & 0\end{array}$ $\begin{array}{lllllllllllll}0 & 0 & 0 & 0 & 0 & 0 & 0 & 0 & 0 & 2 & 0 & 0\end{array}$ $\begin{array}{llllllllllll}0 & 3 & 0 & 0 & 0 & 0 & 3 & 0 & 0 & 2 & 0 & 0\end{array}$ \begin{tabular}{ll|llllllllll}
1 & 0 & 1 & 0 & 0 & 0 & 1 & 1 & 0 & 0 & 0
\end{tabular} $\begin{array}{llllllllllll}3 & 4 & 3 & 3 & 3 & 2 & 0 & 2 & 3 & 5 & 0 & 3\end{array}$ $\begin{array}{llllllllllll}2 & 2 & 2 & 1 & 3 & 1 & 3 & 2 & 2 & 3 & 1 & 1\end{array}$ $\begin{array}{llllllllllll}0 & 3 & 0 & 1 & 0 & 1 & 0 & 0 & 0 & 3 & 0 & 0\end{array}$ $\begin{array}{llllllllllll}0 & 3 & 2 & 2 & 1 & 1 & 2 & 3 & 4 & 3 & 2 & 1\end{array}$ $\begin{array}{llllllllllll}0 & 0 & 0 & 0 & 1 & 0 & 0 & 0 & 0 & 0 & 0 & 0\end{array}$ $\begin{array}{llllllllllll}0 & 0 & 0 & 0 & 1 & 0 & 0 & 0 & 0 & 0 & 0 & 0\end{array}$ \begin{tabular}{lllll|l|llll}
0 & 0 & 0 & 1 & 0 & 3 & 3 & 0 & 0 & 0
\end{tabular} \begin{tabular}{lllll|l|l|l|l|l|l|l|l|l|l|l}
0 & 0 & 0 & 0 & 0 & 1 & 3 & 0 & 0
\end{tabular} $\begin{array}{llllllllllll}0 & 1 & 0 & 0 & 0 & 0 & 0 & 0 & 0 & 1 & 0 & 0\end{array}$ $\begin{array}{llllllllllll}1 & 1 & 0 & 1 & 0 & 0 & 0 & 0 & 0 & 1 & 1 & 1\end{array}$ $\begin{array}{llllllllllll}0 & 0 & 0 & 0 & 0 & 0 & 0 & 0 & 2 & 0 & 0 & 0\end{array}$ $\begin{array}{lllllllllllll}0 & 0 & 0 & 0 & 0 & 0 & 0 & 0 & 0 & 1 & 0 & 0\end{array}$ \begin{tabular}{|llllllll|llll}
0 & 1 & 0 & 0 & 0 & & 1 & & $\mid 1$ & 1 & 0 & 0 \\
& 3 & 0 & 0 & 0 & 0 & 0 & 0 & 3 & 2 & 0 & 0
\end{tabular} $\begin{array}{llllllllllll}0 & 0 & 0 & 2 & 0 & 0 & 0 & 0 & 0 & 2 & 0 & 0\end{array}$ $\begin{array}{llllllllllll}0 & 4 & 0 & 4 & 2 & 0 & 0 & 0 & 0 & 0 & 0 & 0\end{array}$ $\begin{array}{lllllllllllll}0 & 3 & 0 & 0 & 0 & 0 & 0 & 0 & 0 & 0 & 0 & 0\end{array}$ $\begin{array}{llllllllllll}0 & 1 & 0 & 0 & 0 & 1 & 0 & 0 & 0 & 3 & 0 & 0\end{array}$ $\begin{array}{llllllllllll}0 & 2 & 0 & 2 & 0 & 0 & 0 & 0 & 0 & 2 & 0 & 0\end{array}$ $\begin{array}{llllllllllll}0 & 0 & 0 & 0 & 0 & 0 & 0 & 0 & 2 & 0 & 0 & 0\end{array}$ $\begin{array}{lllllllllllll}0 & 0 & 0 & 0 & 0 & 0 & 0 & 0 & 0 & 3 & 0 & 0\end{array}$ $\begin{array}{llllllllllll}2 & 1 & 2 & 0 & 0 & 0 & 2 & 2 & 1 & 1 & 2 & 2\end{array}$ $\begin{array}{llllllllllll}0 & 3 & 0 & 2 & 2 & 0 & 0 & 0 & 0 & 4 & 0 & 0\end{array}$ \begin{tabular}{llllllll|llll}
0 & 0 & 0 & 3 & 0 & 1 & 0 & 0 & 0 & 0
\end{tabular} $\begin{array}{llllllllllll}0 & 0 & 0 & 2 & 0 & 0 & 0 & 0 & 0 & 0 & 0 & 1\end{array}$ $\begin{array}{llllllllllll}0 & 2 & 0 & 0 & 0 & 0 & 0 & 0 & 0 & 0 & 0 & 0\end{array}$ $\begin{array}{lllllllllllllllll}0 & 0 & 0 & 0 & 0 & 1 & 0 & 0 & 1 & 0 & 0 & 0\end{array}$ $\begin{array}{llllllllllll}1 & 1 & 2 & 2 & 2 & 2 & 2 & 2 & 1 & 2 & 2 & 2\end{array}$ $\begin{array}{llllllllllll}1 & 1 & 2 & 2 & 2 & 2 & 2 & 2 & 1 & 2 & 2 & 2 \\ 0 & 0 & 0 & 0 & 0 & 0 & 0 & 0 & 0 & 1 & 0 & 0\end{array}$ $\begin{array}{lllllllllllll}0 & 1 & 2 & 0 & 0 & 0 & 0 & 1 & 0 & 3 & 0 & 0\end{array}$

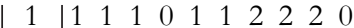

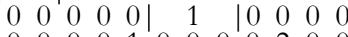
$\begin{array}{llllllllllll}0 & 0 & 0 & 0 & 1 & 0 & 0 & 0 & 0 & 2 & 0 & 0\end{array}$ $\begin{array}{llllllllllll}1 & 2 & 1 & 2 & 2 & 2 & 1 & 1 & 1 & 3 & 3 & 2\end{array}$ $\begin{array}{llllllllllll}0 & 0 & 0 & 1 & 2 & 2 & 0 & 1 & 3 & 4 & 3 & 1\end{array}$

\begin{tabular}{l}
\hline Species \\
Delphineis surirella (Ehrenberg) \\
Andrews \\
Diploneis lineata (Donkin) Cleve \\
Diploneis smithii (Brébisson) Cleve \\
Diploneis splendida Cleve \\
Dityllum brightwellii (West) Grunow
\end{tabular}

Diploneis splendida Cleve

Ditylum brightwellii (West) Grunow

Entomoneis paludosa (W. Smith) Reimer

= Amphiprora paludosa Smith

Eucampia cornuta (Cleve) Grunow

Eucampia zodiacus Ehrenberg

Fragilariopsis oceanica (Cleve) Hasle

Grammatophora marina (Lyngbye)

Kützing

Guinardia delicatula (Cleve) Hasle =

Rhizosolenia delicatula Cleve Rhizosolenia stolterfothii Peragallo

Gyrosigma fasciola Ehrenberg

Hemiaulus hauckii Grunow

Hemiaulus membranaceus Cleve

Hemiaulus sinensis Greville

Leptocylindrus danicus Cleve

Leptocylindrus mediterraneus (Peragallo) Hasle

Leptocylindrus minimus Gran

Licmophora abbreviata Agardh

Liriogramma sarcophagus (Wallich) Lan

= Asteromphalus sarcophagus Wallich

Melosira moniliformis (Müller) Agardh

Navicula cancellata Donkin

Navicula directa (Smith) Ralfs in

Pritchard

Navicula granii (Jørgensen) Gran

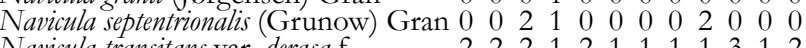
avicula transitans var. derasa $\mathrm{f}$.

delicatula Heimdal

Navicula vanhoeffenii Gran

Nitzschia distans Gregory

Nitzschia fontifuga Cholnoky

Nitrschia frigida Grunow

Month $\begin{array}{llllllllllll}0 & 0 & 2 & 0 & 0 & 4 & 0 & 0 & 0 & 2 & 0 & 0 \\ 0 & 0 & 0 & 0 & 0 & 0 & 0 & 0 & 0 & 0 & 1 & 0\end{array}$ Grunow

rébisson) Ralfs

Odontella aurita (Lyngbye) Agardh

Paralia sulcata (Ehrenberg) Cleve

Pleurosigma formosum Smith

$\begin{array}{llllllllllll}0 & 0 & 0 & 0 & 0 & 0 & 0 & 0 & 0 & 0 & 1 & 0\end{array}$ $\begin{array}{llllllllllll}0 & 1 & 1 & 1 & 1 & 1 & 1 & 2 & 1 & 2 & 0 & 1 \\ 0 & 0 & 0 & 0 & 0 & 0 & 0 & 0 & 1 & 1 & 0 & 0\end{array}$ $\begin{array}{llllllllllll}1 & 1 & 0 & 1 & 0 & 2 & 2 & 3 & 3 & 3 & 2 & 1\end{array}$ \begin{tabular}{lll|lllllll}
0 & 1 & 1 & 0 & 0 & 0 & 0 & 2 & 0 & 0
\end{tabular}

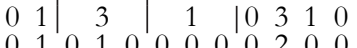
$\begin{array}{llllllllllll}1 & 1 & 2 & 2 & 3 & 2 & 2 & 2 & 2 & 2 & 2 & 2\end{array}$

$\begin{array}{llllllllllll}0 & 2 & 0 & 0 & 0 & 0 & 0 & 0 & 2 & 2 & 0 & 1\end{array}$

$\begin{array}{llllllllllll}0 & 1 & 0 & 0 & 1 & 0 & 0 & 0 & 0 & 2 & 0 & 0\end{array}$ $\begin{array}{llllllllllll}1 & 1 & 0 & 1 & 0 & 0 & 0 & 1 & 3 & 3 & 0 & 1\end{array}$ $\begin{array}{llllllllllll}0 & 0 & 0 & 0 & 0 & 0 & 0 & 0 & 1 & 0\end{array}$ $\begin{array}{llllllllllll}1 & 1 & 0 & 0 & 0 & 0 & 0 & 0 & 1 & 2 & 0 & 0\end{array}$ $\begin{array}{llllllllllll}0 & 2 & 0 & 2 & 1 & 2 & 0 & 4 & 1 & 4 & 2 & 0\end{array}$ $\begin{array}{lllllllllllllllllll}0 & 2 & 0 & 2 & 0 & 2 & 0 & 0 & 0 & 3 & 0 & 0\end{array}$ $\begin{array}{llllllllllll}2 & 2 & 3 & 3 & 2 & 3 & 1 & 2 & 2 & 2 & 2 & 2\end{array}$ $\begin{array}{llllllllllll}0 & 0 & 0 & 0 & 0 & 0 & 0 & 0 & 0 & 2 & 0 & 0\end{array}$ $\begin{array}{llllllllllll}1 & 1 & 3 & 1 & 1 & 1 & 0 & 1 & 0 & 2 & 0 & 1\end{array}$ $\begin{array}{lllllllllllll}0 & 0 & 0 & 1 & 0 & 0 & 0 & 0 & 0 & 0 & 0 & 0\end{array}$ $\begin{array}{lllllllllllll}2 & 2 & 3 & 2 & 2 & 2 & 1 & 1 & 1 & 2 & 2 & 2\end{array}$

$\begin{array}{llllllllllll}0 & 0 & 2 & 1 & 0 & 0 & 0 & 0 & 2 & 0 & 0 & 0 \\ 2 & 2 & 2 & 1 & 2 & 1 & 1 & 1 & 1 & 3 & 1 & 2\end{array}$

$\begin{array}{llllllllllllllll}0 & 0 & 2 & 2 & 2 & 1 & 1 & 0 & 0 & 0 & 0 & 0\end{array}$ $\begin{array}{llllllllllllllllll}0 & 0 & 1 & 0 & 1 & 0 & 0 & 0 & 0 & 0 & 0 & 0\end{array}$ $\begin{array}{lllllllllllll}0 & 0 & 0 & 0 & 0 & 1 & 0 & 0 & 0 & 0 & 0 & 0\end{array}$

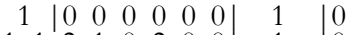
\begin{tabular}{llllllll|l|l}
1 & 1 & 2 & 1 & 0 & 2 & 0 & 0 & 1 & 0
\end{tabular} $\begin{array}{llllllllllll}1 & 2 & 4 & 2 & 1 & 2 & 1 & 1 & 1 & 2 & 1 & 1\end{array}$ $\begin{array}{lllllllllllll}0 & 0 & 0 & 0 & 1 & 0 & 0 & 0 & 0 & 0 & 0 & 0\end{array}$ $\begin{array}{llllllllllll}1 & 2 & 2 & 1 & 2 & 2 & 1 & 2 & 3 & 3 & 1 & 2\end{array}$

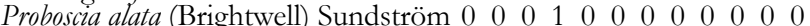
$\begin{array}{lllllllllllll}\text { Pseudo-nitzschia americana (Hasle) } & 0 & 2 & 0 & 2 & 1 & 0 & 0 & 0 & 0 & 0 & 0 & 0\end{array}$ Fryxell

Pseudo-nitsschia calliantha* Lundholm, $\begin{array}{lllllllllllll}0 & 1 & 0 & 0 & 2 & 0 & 0 & 0 & 0 & 4 & 2 & 0\end{array}$ Hasle et Moestrup

Pseudo-nitzschia fraudulenta* (Cleve)

Hasle

Pseudo-nitrschia multistriata* Takano

Pseudo-nitzschia pungens* (Grunow ex

Cleve) Hasle

Psendo-nitzschia pseudodelicatissima*

Hasle

Psendo-nitzschia seriata* (Cleve)

Peragallo

Pyxidicula nipponica (Gran et Yendo) Strelnikova et Nikolaev

Rhizosolenia bebetata f. bebetata Bailey

Rhizosolenia bebetata $\mathrm{f}$. semispina

(Hensen) Gran

Rhizosolenia pungens Cleve-Euler

Rhizosolenia setigera Brightwell

Sketetonema costatum (Greville) Cleve

Skeletonema dohrnii Sarno et Kooistra

Skeletonema grethae Zingone et Sarno

Skeletonema japonicum Zingone et

Sarno

Skeletonema marinoi Sarno et Zingone

Skeletonema spp.

Stephanopyxis turris (Greville) Ralfs

Synedra sp. $\begin{array}{lllllllllllll}\text { Synedra sp. } & 0 & 0 & 1 & 0 & 0 & 0 & 0 & 0 & 0 & 0 & 0 & 0 \\ \text { Tabularia fasciculata (Agardh) Williams } & 0 & 1 & 0 & 1 & 0 & 1 & 0 & 0 & 0 & 0 & 0 & 0\end{array}$ et Round

Thalassionema frauenfeldii (Grunow)

Hallegraeff

Hallegraeff

halassionema nitzschic

Thalassiosira gravida Cleve

Thalassiosira leptopus (Grunow ex

Van Heurck) Hasle et Fryxell =

Coscinodiscus lineatus Ehrenberg

Thalassiosira mala Takano

$\begin{array}{lllllllllllll}0 & 1 & 0 & 1 & 0 & 0 & 0 & 0 & 0 & 0 & 0 & 0\end{array}$

$\begin{array}{lllllllllllll}0 & 2 & 0 & 1 & 0 & 0 & 1 & 2 & 3 & 4 & 3 & 0\end{array}$ $\begin{array}{llllllllllll} & 2 & 1 & 1 & 1 & 1 & 0 & 3 & 2 & 4 & 3 & 2\end{array}$ \begin{tabular}{ll|l|l|l|l|l|l|l|l|l|l|l|l|l|l|l|l}
0 & 0 & 3 & 3 & 4 & 0
\end{tabular} $\begin{array}{llllllllllll}0 & 0 & 0 & 0 & 0 & 0 & 0 & 0 & 0 & 2 & 0 & 0\end{array}$

$\begin{array}{llllllllllll}1 & 1 & 1 & 0 & 0 & 0 & 0 & 0 & 0 & 0 & 0 & 0\end{array}$

$\begin{array}{llllllllllll}0 & 0 & 0 & 1 & 0 & 0 & 0 & 0 & 0 & 1 & 0 & 0 \\ 0 & 0 & 0 & 0 & 0 & & 1 & & & 1 & \end{array}$

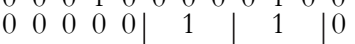
$\begin{array}{llllllllllll}0 & 1 & 0 & 0 & 0 & 0 & 0 & 0 & 1 & 3 & 0 & 1\end{array}$ $\begin{array}{llllllllllll}1 & 2 & 2 & 1 & 2 & 2 & 2 & 3 & 2 & 4 & 3 & 2\end{array}$ $\begin{array}{lllllllllllll}0 & 0 & 0 & 0 & 0 & 3 & 0 & 0 & 0 & 0 & 0 & 0\end{array}$ $\begin{array}{lllllllllllll}0 & 0 & 0 & 0 & 0 & 1 & 2 & 3 & 5 & 0 & 0 & 0\end{array}$ $\begin{array}{llllllllllll}0 & 0 & 0 & 0 & 0 & 0 & 0 & 0 & 1 & 0 & 0 & 0\end{array}$ $\begin{array}{llllllllllll}0 & 0 & 0 & 0 & 0 & 0 & 0 & 0 & 2 & 5 & 6 & 0\end{array}$ $\begin{array}{llllllllllll}0 & 0 & 0 & 0 & 0 & 0 & 0 & 0 & 2 & 0 & 0 & 0\end{array}$ $\begin{array}{llllllllllll}2 & 2 & 2 & 1 & 2 & 0 & 6 & 4 & 0 & 6 & 6 & 3\end{array}$ $\begin{array}{llllllllllll}0 & 0 & 0 & 0 & 0 & 0 & 1 & 0 & 0 & 0 & 0 & 0\end{array}$

223223333432 2253111213345542 $\begin{array}{llllllllllll}0 & 1 & 0 & 0 & 1 & 0 & 0 & 0 & 0 & 0 & 0 & 0\end{array}$ $\begin{array}{llllllllllllll}0 & 0 & 0 & 0 & 0 & 0 & 0 & 0 & 1 & 0 & 0 & 0\end{array}$ $\begin{array}{llllllllllll}0 & 0 & 0 & 0 & 0 & 0 & 1 & 1 & 0 & 0 & 0 & 0\end{array}$ 
Table 2. Continued.

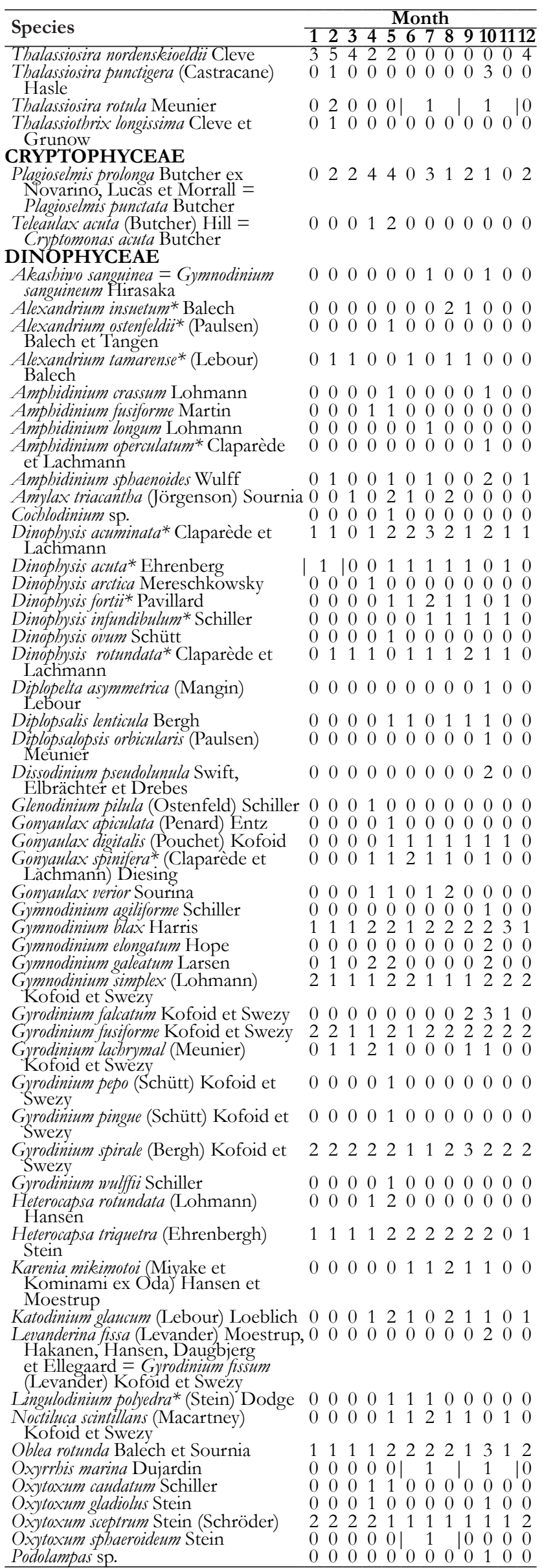

Species

Pronoctiluca pelagica Fabre-Domer

Prorocentrum emarginatum Fukuyo

Prorocentrum foraminosum * Faust

Prorocentrum micans Ehrenberg

Prorocentrum minimum* (Pavillard)

Schiller

Prorocentrum triestinum Shiller

Protoceratium reticulatum* (Claparède et $\begin{array}{llllllllllllllll}0 & 0 & 1 & 0 & 1 & 1 & 1 & 2 & 2 & 1 & 0 & 0\end{array}$

Lachmann) Butschli

Protoperidinium abei (Paulsen) Balech $\begin{array}{lllllllllllll}0 & 0 & 0 & 1 & 0 & 0 & 0 & 0 & 0 & 0 & 0 & 0\end{array}$

Protoperidinium bipes (Paulsen) Balech $\begin{array}{lllllllllllll}1 & 1 & 1 & 1 & 1 & 0 & 3 & 2 & 2 & 2 & 2 & 2\end{array}$

Protoperidinium brevipes (Paulsen)

Balech

Protoperidinium claudicans (Paulsen)

Balech

Protoperidinium conicoides (Paulsen)

Balech

Protoperidinium conicum (Gran) Balech $1 \begin{array}{llllllllllll}1 & 0 & 0 & 1 & 1 & 1 & 2 & 2 & 1 & 2 & 2 & 1\end{array}$

$\begin{array}{llllllllllllllll}\text { Protoperidinium crassipes Kofoid } & 0 & 0 & 0 & 0 & 1 & 1 & 0 & 0 & 0 & 1 & 0 & 0\end{array}$

Protoperidinium curtipes (Jörgensen)
Balech

$\begin{array}{llllllllllllll}0 & 1 & 0 & 1 & 1 & 2 & 0 & 0 & 0 & 1 & 0 & 1\end{array}$

$\begin{array}{llllllllllllllllll}0 & 0 & 0 & 1 & 0 & 0 & 1 & 0 & 0 & 1 & 0 & 0\end{array}$

$\begin{array}{lllllllllllll}0 & 1 & 0 & 0 & 0 & 1 & 0 & 0 & 0 & 1 & 0 & 1\end{array}$

Protoperidinium curvipes (Ostenfeld)
Balech

Protoperidinium depressum (Bailey)
Balech

Protoperidinium divaricatum (Meunier) Parke et Dodge

Protoperidinium divergens (Ehrenberg) Balech

Protoperidinium granii (Ostenfeld) Balech

Protoperidinium latidorsale (Dangeard) $\quad \begin{array}{llllllllllll}0 & 0 & 0 & 0 & 0 & 0 & 0 & 1 & 1 & 0 & 0 & 0\end{array}$ Balech

Protoperidinium leonis (Pavillard) Balech \begin{tabular}{lllll|llllll}
0 & 0 & 1 & 1 & $1 \mid$ & 1 & $\mid$ & 1 & 0 & 0
\end{tabular} $\begin{array}{cccccccccccc}\text { Protoperidinium marukawai (Abé) } & 0 & 0 & 0 & 0 & 1 & 0 & 0 & 0 & 0 & 0 & 0\end{array}$ Balech

Protoperidinium minutum (Kofoid) Loeblich

Protoperidinium mite (Pavillard) Balech $\begin{array}{lllllllllllll}0 & 0 & 0 & 0 & 1 & 1 & 0 & 0 & 0 & 0 & 0 & 0\end{array}$ $\begin{array}{llllllllllllll}\text { Protoperidinium monovelum (Abé) } & 1 & 1 & 1 & 0 & 1 & 0 & 1 & 1 & 0 & 1 & 0 & 0\end{array}$ Batech

Protoperidinium oblongum (Aurivillius) $\quad \begin{array}{llllllllllll}0 & 0 & 0 & 0 & 0 & 0 & 0 & 0 & 0 & 1 & 0 & 0\end{array}$ Parke et Dodge

Protoperidinium obtusum (Karsten)

Parke et Dodge Protoperidinin
Balech

Protoperidinium ovum (Schiller) Balech $\begin{array}{lllllllllllll}0 & 0 & 0 & 0 & 0 & 0 & 0 & 0 & 0 & 2 & 0 & 0\end{array}$ $\begin{array}{lllllllllllllll}\text { Protoperidinium pallidum (Ostenfeld) } & 0 & 1 & 0 & 1 & 1 & 0 & 1 & 0 & 0 & 0 & 0 & 0\end{array}$ Balech

Protoperidinium pellucidum Bergh

Protoperidinium pentagonum (Gran)

Balech

Protoperidinium punctulatum (Paulsen) Balech

Protoperidinium pyriforme (Paulsen)

$\begin{array}{llllllllllll}1 & 1 & 2 & 2 & 2 & 2 & 2 & 2 & 2 & 2 & 2 & 2\end{array}$ $\begin{array}{llllllllllll}0 & 0 & 0 & 0 & 1 & 1 & 1 & 1 & 1 & 1 & 0 & 0\end{array}$

$\begin{array}{lllllllllllll}0 & 0 & 0 & 0 & 1 & 0 & 0 & 0 & 0 & 0 & 0 & 0\end{array}$

Protoperidinium quarnerense (Schröder) $00 \begin{array}{lllllllllll}0 & 0 & 0 & 0 & 0 & 0 & 0 & 1 & 0 & 0 & 0\end{array}$ Balech

Protoperidinium steinii (Jörgensen)
Balech

Protoperidinium subinerme (Paulsen) Loeblich

Protoperidinium thorianum (Paulsen)

Balech

Pyrocystis lunula (Schütt) Schütt

Pyrophacus horologium Stein

$\begin{array}{lllllllllllll}0 & 0 & 0 & 0 & 1 & 1 & 0 & 1 & 1 & 2 & 1 & 0\end{array}$ $\begin{array}{lllllllllllll}0 & 0 & 0 & 0 & 1 & 0 & 0 & 0 & 1 & 1 & 0 & 1\end{array}$ $\begin{array}{lllllllllllllllll}0 & 1 & 1 & 1 & 1 & 1 & 1 & 1 & 1 & 1 & 0 & 0\end{array}$ $\begin{array}{llllllllllllllll}0 & 0 & 0 & 0 & 0 & 0 & 0 & 0 & 1 & 1 & 0 & 0\end{array}$ $\begin{array}{lllllllllllllllll}0 & 0 & 1 & 1 & 1 & 1 & 2 & 2 & 2 & 1 & 0 & 1\end{array}$ Pyrophacus steinii (Shiller) Wall et Dale $\begin{array}{lllllllllllll}0 & 0 & 0 & 0 & 0 & 0 & 0 & 0 & 1 & 1 & 0\end{array}$ Scrippsiella trochoidea (Stein) Loeblich $\quad \begin{array}{llllllllllll}0 & 1 & 0 & 1 & 2 & 2 & 3 & 3 & 2 & 2 & 1 & 1\end{array}$

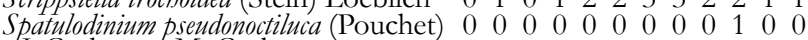
Spatulodinium pseudonoctiluca

$\begin{array}{lllllllllllllll}\text { J. Cachon et M. Cachon } \\ \text { Torodinium robustum Kofoid et Swezy } & 0 & 0 & 0 & 0 & 1 & 0 & 0 & 0 & 0 & 1 & 0 & 0\end{array}$ Tripos engrammus (Ehrenberg) Gómez $\begin{array}{llllllllllllllllll}0 & 0 & 0 & 0 & 0 & 0 & 0 & 0 & 0 & 2 & 0 & 0\end{array}$ = Ceratium furca var. engrammum

(Ehrenberg) Schiller

Tripos furca (Ehrenberg) Gómez = Ceratium furca (Ehrenberg)

Claparède et Lachmann

Tripos fusus (Ehrenberg) Gómez = $\begin{array}{llllllllllll}0 & 0 & 0 & 0 & 1 & 0 & 2 & 2 & 2 & 3 & 1 & 0\end{array}$ Ceratium fusus (Ehrenberg) Dujardin

Tripos kofoidii (Jörgensen) Gomez = $\begin{array}{llllllllllll}0 & 0 & 0 & 0 & 0 & 0 & 0 & 0 & 0 & 2 & 0 & 0\end{array}$ Ceratium kofoidii Jörgensen

Tripos muelleri Bory = Ceratium tripos $\quad \begin{array}{lllllllllllll}0 & 0 & 0 & 0 & 1 & 0 & 0 & 0 & 0 & 0 & 0 & 0\end{array}$ Tripos seta (Ehrenberg) Gómez =

Tripos seta (Ehrenberg) Gomez $=$
Ceratium fusus var. seta (Ehrenberg) Jörgensen $\begin{array}{llllllllllll}0 & 0 & 0 & 0 & 0 & 0 & 0 & 0 & 0 & 2 & 0 & 0\end{array}$$$
\text { r) }
$$ 
Table 2. Continued.

\begin{tabular}{|c|c|c|c|}
\hline Species & $\begin{array}{c}\text { Month } \\
123456789101112\end{array}$ & Species & $\begin{array}{c}\text { Month } \\
123456789101112\end{array}$ \\
\hline ЛРНУCEAF & & Eutreptie & $\begin{array}{llllllllllll}0 & 1 & 0 & 3 & 1 & 0 & 0 & 0 & 0 & 0 & 0 & 0\end{array}$ \\
\hline $\begin{array}{l}\text { Monor } \\
\text { Hin } \\
\text { Kor }\end{array}$ & $\begin{array}{llllllllllll}0 & 0 & 0 & 0 & 0 & 0 & 0 & 0 & 0 & 1 & 0 & 0\end{array}$ & $\begin{array}{l}\text { Moestrup et } \\
\text { hiller) Pascher }\end{array}$ & $\begin{array}{lllllllllll}0 & 1 & 0 & 0 & 2 & 0 & 0 & 0 & 0 & 0 & 0\end{array}$ \\
\hline Pyran & $\begin{array}{llllll}0 & 2 & 2 & 0 & 0\end{array}$ & & \\
\hline madricauda (Tu1 & \begin{tabular}{lllll|l}
0 & 0 & 0 & 1 & 0
\end{tabular} & 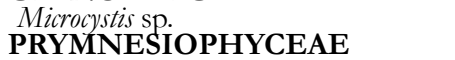 & \begin{tabular}{lllll|l}
0 & 0 & 0 & 0 & 0
\end{tabular} \\
\hline $\begin{array}{l}\text { EUGLENOIDEA } \\
\text { Eutreptia lanowii Steuer }\end{array}$ & $\begin{array}{llllllllllll}2 & 2 & 2 & 2 & 3 & 1 & 1 & 2 & 5 & 1 & 1 & 1 \\
\end{array}$ & $\begin{array}{l}\text { Daptolina sorokemu St } \\
\text { ova et Orlova }\end{array}$ & $\begin{array}{llllllllllll}0 & 3 & 6 & 0 & 0 & 0 & 0 & 0 & 0 & 0 & 0 & 0\end{array}$ \\
\hline
\end{tabular}

Note: $*$ - potentially toxic. " 0 " - absence of species in the sample, " $1-6$ " - abundance of species (in combined cells with side borders -

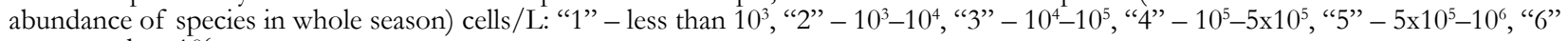
- greater than $10^{6}$

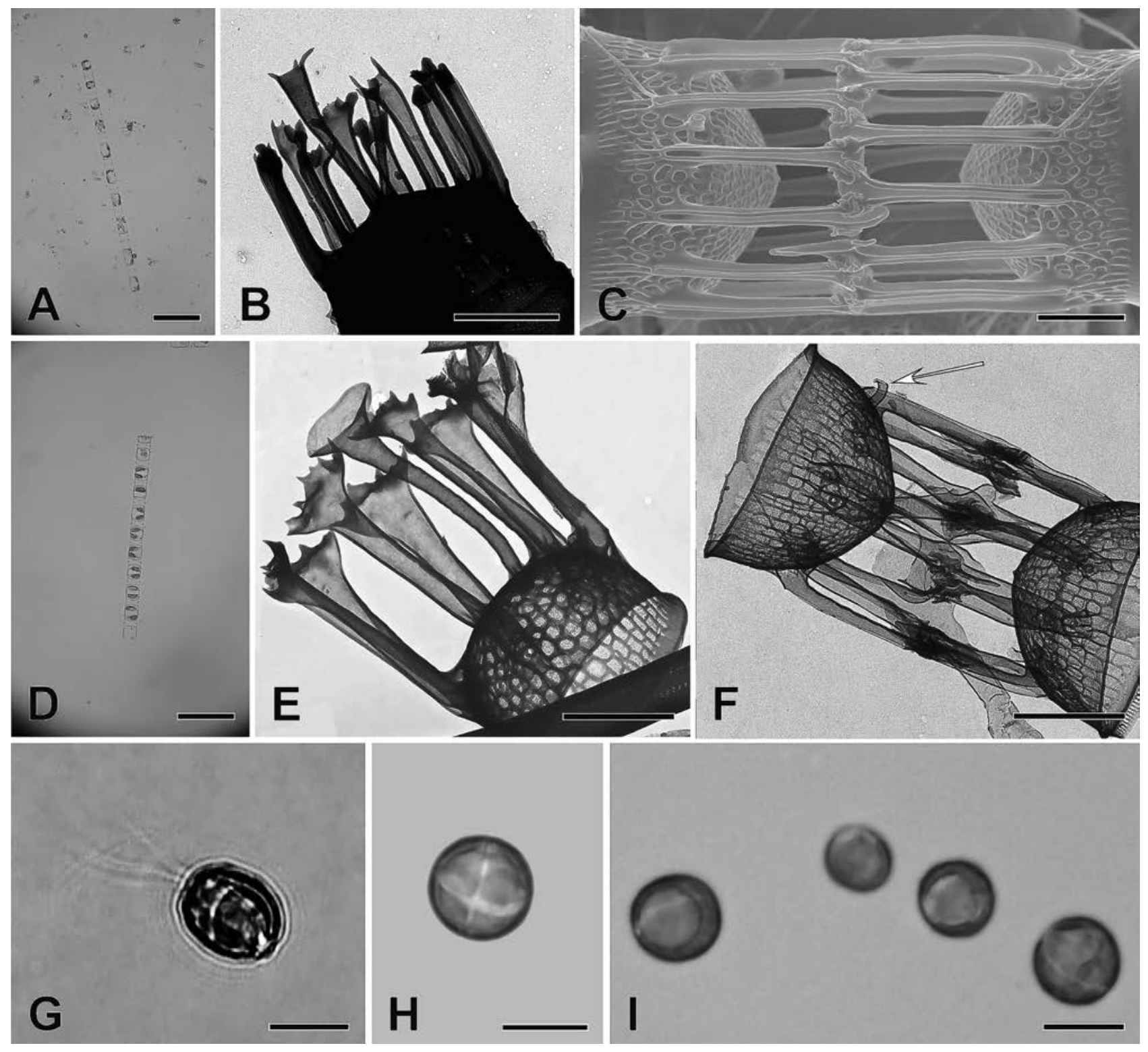

Figure 3 Skeletonema japonicum Zingone et Sarno 2005: A - general appearance of colony, B - terminal valve, long rimoportula process with denticles at edge, $\mathrm{C}$ - intercalary valves, linkage of fultoportula processes; Skeletonema marinoi Sarno et Zingone 2005: D - colony of cells, E - terminal valve, rimoportula process flared distally, F - intercalary valves, rimoportula process (arrowhead); Pseudohaptolina sorokinii Stonik, Efimova et Orlova 2016: G - cell with two flagella and one haptonema, $\mathrm{H}$ - cell with four chloroplasts, I - cells in plankton. A, D, G-I LM, B, E, F - TEM, C - SEM. Scale: B, C, E, F $=2 \mu \mathrm{m}, A, C, G-I=10 \mu \mathrm{m}, \mathrm{D}=20 \mu \mathrm{m}$ 
2007, Kooistra et al. 2008). In the Sea of Japan the species is known from off Kyushu Island (Yamada et al. 2010).

Skeletonema dohrnii Sarno et Kooistra 2005 (Fig. 2: C-E)

Description. Cells cylindrical, $2.7-10.8 \mu \mathrm{m}$ in diameter, forming slightly curved colonies of 2-104 cells; with 1-2 chloroplasts per cell. Valves circular, slightly convex. Fultoportula processes straight, 6 to 29 on each valve. Terminal fultoportula processes widened, with denticles along the margin. The intercalary rimoportula process in the shape of a narrow low tube; situated near the valve margin. The terminal rimoportula process located close to the valve center.

Distribution. Widely distributed in the World Ocean, mainly in the temperate zone of the Pacific Ocean (from $52^{\circ} \mathrm{N}$ to $39^{\circ} \mathrm{S}$ ); absent in tropical waters (Zingone et al. 2005 , Kooistra et al. 2008). In the Sea of Japan first recorded from off the coast of Japan in Dokai Bay (Yamada et al. 2010).

Skeletonema grethae Zingone et Sarno 2005 (Fig. 2: F-H)

Description. Cells cylindrical, $5.5-10.3 \mu \mathrm{m}$ in diameter, with 1-2 chloroplasts per cell. Colonies straight or slightly curved, consisting of 20-60 cells. Valves circular, convex. Fultoportula processes straight, long, 14 to 18 on each valve. Terminal fultoportula processes have a claw-like projection located distally. The intercalary rimoportula process in the shape of a short narrow tube; located close to the valve margin. The terminal valve bears an eccentrically situated rimoportula in the form of a long tube flared distally.

Distribution. Off the coast of Brazil and in Narragansett Bay (the Atlantic Ocean) (Sarno et al. 2005, Bergesch et al. 2009).

Skeletonema japonicum Zingone et Sarno 2005 (Fig. 3: A-C)

Description. Cells cylindrical, 3.0-7.6 $\mu \mathrm{m}$ in diameter, with 2-4 chloroplasts per cell, joined into straight colonies of 3 to 23 cells. Valves circular, slightly convex. Intercalary rimoportula process in the form of a narrow short tube; situated near the valve margin. Terminal rimoportula process is a long, distally widened tube located close to the center. Fultoportula processes straight, long, 6 to 37 on each valve. Terminal fultoportula processes slightly widened distally, with dentate margins.

Distribution. Mainly in the temperate zone of the $\mathrm{Pa}$ cific Ocean and in the tropical upwelling zones (Kooistra et al. 2008). In the Sea of Japan it is found along the Korean Peninsula (Kooistra et al. 2008) and Kyushu Island (Yamada et al. 2010).

\section{Skeletonema marinoi Sarno et Zingone 2005 (Fig. 3: D-F)}

Description. Cells cylindrical, $2.0-7.0 \mu \mathrm{m}$ in diameter, with 1-2 chloroplasts per cell, united into straight or slightly curved colonies of 15 to 30 cells. Valves rounded, slightly convex. The intercalary rimoportula process is a short narrow tube located close to the center of the valve. The terminal rimoportula process in the shape of a long tube flared distally; located close to the center of the valve. Fultoportula processes straight, long, 7 to 11 on each valve. Terminal fultoportula processes strongly widened distally.

Distribution. This cosmopolitan species, absent in the Antarctic waters, is reported from latitudes between $08^{\circ} \mathrm{S}$ and $58^{\circ} \mathrm{N}$ (Koostra et al. 2008). In the Sea of Japan it occurs off the coast of Japan in Dokai Bay (Yamada et al. 2010).

Pseudohaptolina sorokinii Stonik, Efimova et Orlova 2016 (Fig. 3: G-I)

Description. Cells rounded, 13-20 $\mu \mathrm{m}$ in diameter. Two flagella and one haptonema are of approximately equal length. Each cell contains four large chloroplasts, which can be well seen particularly at the moment when the cell dies.

Distribution. Amur Bay (the northwestern Sea of Japan) (Orlova et al. 2016).

Algal bloom of Pseudohaptolina. sorokinii and Skeletonema japonicum was documented in the coastal waters of Russky Island for the first time. Diatoms Asteromphalus flabellatus, Liriogrammas arcophagus and dinoflagellates Dinophysis arctica, Gymnodinium elongatum, Protoperidinium divaricatum were first reported from the northwestern Sea of Japan; their abundance did not exceed $1 \times 10^{3}$ cells $/ \mathrm{L}$.

A total of 20 species of potentially toxic microalgae were identified from the study area (Table 2). Diatoms of the genus Pseudo-nitzschia, as well as dinoflagellates of the genera Alexandrium, Dinophysis and Prorocentrum were present in the phytoplankton all year round. Dinoflagellates Amphidinium operculatum, Alexandrium ostenfeldii and Prorocentrum foraminosum, in low concentrations, were observed in different seasons of the year; each of the species was reported once. The other species of potentially toxic microalgae were recorded mainly in summer.

\section{DISCUSSION}

The phytoplankton of the Ussuri Bay, before this study, was known only from Selina (1988), who carried out research from April to September of 1983 and provided the list of 80 microalgal species, and Begun (2004), who studied species composition and abundance of phytoplankton in 2001-2002 and recorded 119 taxa. In Amur Bay, 357 species from 8 orders were recorded in the course of a long-term research by Orlova et al. (2009).

During the study period, two species causing water bloom in the coastal waters of Russky Island (Skeletonema japonicum and Pseudohaptolina sorokinii) were identified. Massive growth of Skeletonema japonicum was recorded in November $\left(\mathrm{t}_{\text {water }}=\right.$ $9{ }^{\circ} \mathrm{C}, \mathrm{S}=33.5 \%$ ). According to the literature, at temperate latitudes species of the genus Skeletonema dominate in the plankton community mainly in winter, spring and summer (Borkman \& Smayda 2009, Degerlund \& Eilertsen 2010). Due to the difficulty in identification of Skeletonema cells at the species level with light microscopy, the quantitative data in Table 2 are given for a complex of species. In the coastal waters off Russky Island Skeletonema spp. occurred in the plankton throughout the year. The electron microscopic investigation of Skeletonema costatum, S. dohrnii, S. grethae, S. japonicum and $S$. marinoi indicated that morphology of the species from the study area, in general, corresponds with original descriptions (Sarno et al. 2005, Zingone et al. 2005).

A bloom of Psendohaptolina sorokinii occured once, in March of 2013; its massive proliferation was observed when the sea ice of the study area started melting $\left(\mathrm{t}_{\text {water }}=-1.2-\right.$ $-0.3^{\circ} \mathrm{C}, \mathrm{S}=13.8-32.5 \%$ ). Psendohaptolina sorokinii, rather re- 
cently described from Amur Bay (Orlova et al. 2016), was recorded in the World Ocean for the second time. The mechanisms causing blooms of microalgae species, which are rare in any water area, are still understudied. Reliable records of cryptic phytoplankton taxa add to our knowledge of their distribution in the World Ocean.

At the same time, it should be noted that the abundance of the species occasionally blooming in adjacent Amur Bay, such as Chaetoceros contortus, C. socislis, C. pseudocrinitus, Dactyliosolen fragilissimus, Nitzschia frigida, Pseudo-nitzschia calliantha, P. multistriata, P. pungens, $P$. pseudodelicatissima, Thalassionema nitaschioides, Thalassiosira nordenskioeldii, dinoflagellates Prorocentrum minimum, P. triestinum, euglena Eutreptia lanowii, did not exceed $5 \times 10^{5}$ cells $/ \mathrm{L}$ in the study area.

Data on species composition and quantitative characteristics of potentially toxic phytoplankton in the coastal waters of Russky Island are among the most important results of the study. Marine biotoxins from microalgae can accumulate in the tissues of filter-feeding shellfish and do no harm to them. But consumption of shellfish that are contaminated with toxins causes poisoning in endotherm animals, birds and humans (Hallegraeff et al. 2003). A total of 33 species of potentially toxic microalgae are known from the northwestern Sea of Japan (Orlova 2013), 28 species are recorded in Amur Bay, and our study provides information on 20 species: Alexandrium insuetum, A. ostenfeldii, A. tamarense, Amphidinium operculatum, Dinophysis acuminata, D. acuta, D. fortii, D. infundibulum, D. rotundata, Gonyaulax spinifera, Lingulodinium polyedra, Prorocentrum foraminosum, P. minimum, Protoceratium reticulatum, Pseudo-nitsschia calliantha, P. fraudulenta, $P$. multistriata, $P$. pungens, $P$. pseudodelicatissima and $P$. seriata. Though the list contains an impressive number of potentially toxic microalgal species reported in the study area, their abundance did not exceed the level safe for humans and marine organisms (Andersen 1996).

The present list should be regarded as a preliminary one. At the same time it can serve as a starting point for further monitoring of phytoplankton in the study water area.

\section{ACKNOWLEDGEMENTS}

The authors express their sincere gratitude to the research scientists of the NSCMB FEB RAS: M.S. Selina, I.V. Stonik, T.V. Morozova, S.I. Maslennikov. The reported study was supported by the RFBR (research project № 19-04-00752).

\section{LITERATURE CITED}

Andersen, P. 1996. Design and implementation of some harmful algal monitoring systems. Intergovernmental Oceanographic Commission technical series 44:1-102.

Begun, A.A. 2004. Phytoplankton in the Golden Horn Bay and the Ussuri Bay (Japan Sea) under conditions of anthropogenic pollution. Iqvestia TINRO 138:320-344 (in Russian). ББегун A.А. 2004. Фитопланктон бухты 3омотой Рог и Уссурийского залива (Японское море) в условиях антропогенного загрязнения // Известия ТИНРО. Вып. 138. С. 320-344].

Bergesch, M., M. Garsia \& C. Odebrecht 2009. Diversity and morphology of Skeletonema species in Southern Brazil, Southwestern Atlantic ocean. Journal of Phycology 45:13481352.
Borkman, D. \& T. Smayda 2009. Multidecadal (1959-1997) changes in Skeletonema abundance and seasonal bloom patterns in Narragansett Bay, Rhode Island, USA. Journal of Sea Research 61:84-94.

Cloern, J.E. \& A.D. Jassby. 2010. Patterns and scales of phytoplankton variability in estuarine-coastal ecosystems. Estuaries and Coasts 33:230-241.

Colijn, F. 1992. Changes in plankton communities: when, where and why. ICES Marine Science Symposia 195:193-212.

Degerlund, M. \& H.C. Eilertsen. 2010. Main species characteristics of phytoplankton spring blooms in NE Atlantic and Arctic waters $\left(68-80^{\circ} \mathrm{N}\right)$. Estuaries and Coasts 33: 242-269.

Greville, R.K. 1866. Description of new and rare diatoms. Series 20. Transactions of the Microscopical Society of London 14:77-86.

Guiry, M.D. \& G.M. Guiry 2012. Algaebase. Last accessed at http://www.algaebase.org, 13 March 2019.

Hallegraeff, G.M., D.M. Anderson \& A.D. Cembella 2003. Manual on Harmful Algal Blooms. UNESCO, 793 pp.

Hasle, G.R. \& G.A. Fryxell. 1970. Diatoms: cleaning and mounting for light and electron microscopy. Transactions of the American Microscopical Society 89:469-474.

Kooistra, W.H.C.F., D. Sarno, S. Balzano, H.Gu, R.A. Andersen \& A. Zingone 2008. Global diversity and biogeography of Skeletonema species (Bacillariophyta). Protist 159: 177-193.

Orlova, T.Y. 2013. Diversity of potentially toxic microalgae on the east coast of Russia. In: Marine Biodiversity and Ecosystem Dynamics of the Northwest Pacific Ocean (S. Song, A.V. Adrianov, K.A. Lutaenko, S. Xiao-Xia, eds), pp. 7791. Science Press, Beijing.

Orlova, T.Yu., I.V. Stonik and O.G. Shevchenko. 2009. Flora of planktonic microalgae of Amursky Bay, Sea of Japan. Russian Journal of Marine Biology 35(1):48-61.

Orlova, T.Yu., K.V. Efimova \& I.V. Stonik 2016. Morphology and molecular phylogeny of Pseudohaptolina sorokinii sp. nov. (Prymnesiales, Haptophyta) from the Sea of Japan, Russia. Phycology 55:506-514.

Sarno, D., W.H.C. Kooistra, L. Medlin, I. Percopo \& A. Zingone 2005. Diversity in the genus Skeletonema (Bacillariophyceae). II. An assessment of the taxonomy of $S$. costatum - like species with the description of four new species. Journal of Phycology 41:151-176.

Sarno, D., W.H.C. Kooistra, S. Balzano, P.E. Hargraves \& A. Zingone 2007. Diversity in the genus Skeletonema (Bacillariophyceae): III. Phylogenetic position and morphological variability of Skeletonema costatum and Skeletonema grevillei, with the description of Skeletonema ardens sp. nov. Journal of Phycology 43:156-170.

Selina, M.S. 1988. Spring-autumn phytoplankton in bays of the Sea of Japan. Trudy DV NIGMI 132:60-68 (in Russian). [Селина М.C. 1988. Весенне-осенний фитопцанктон в заливах Японского моря // Труды АВНИГМИ. Вып. 132. С. 60-68].

Shevchenko, O.G. \& A.A. Ponomareva 2015. The morphology and ecology of the marine diatom Skeletonema marinoi Sarno et Zingone, 2005 from the Sea of Japan. Russian Journal of Marine Biology 41(6):453-456.

Sukhanova, I.N. 1983. Concentration of phytoplankton in the sample. In: Modern methods of quantifying the distribution of marine plankton (M.E. Vinogradov, ed.), pp. 97-105, 
Nauka, Moscow (in Russian). [Суханова И.Н. 1983. Концентрирование фитопланктона в пробе // Coвременные методы количественной оценки распреАеления морского планктона / под реА. М.Е. Виноградова. М.: Наука. С. 97-105].

Utermöhl, H. 1958. Zur Vervollkommnung der quntitativen Phytoplankton. Methodik. Mitteilungen der IVL 9: 1-38.

Yamada, M., E. Katsuki, M. Otsubo, M. Kawaguchi, K. Ichimi, H. Kaeriyama, K. Tada \& P. Harrison 2010. Species diversity of the genus Skeletonema (Bacillariophyceae) in the industrial harbor Dokai Bay. Japan Journal of Oceanography 66: 755-771.

Zingone, A., I. Percopo, P.A. Sims \& D. Sarno 2005. Diversity in the genus Sceletonema (Bacillariophyceae). I. A reexamination of the type material of $S$. costatum with the description of $S$. grevillei sp. nov. Journal of Phycology 41: 140-150. 